 $\neg \hbar$
}

\begin{abstract}
$\underset{\text { (南京大学大地海洋科学累, 南紊210008) }}{\text { 海 }}$
8 提要 50 年代至 80 年代切，新型平原沙漠区湖泊普遍处于退缩犾态，一些湖泊干涸或基 本干洞、这是湖泊所在流域上、中游地区湖济事业发展的必然结果。到目前为止, 湖泊干缩所引起 生态环境的变化,其范围主要限于湖周右限区域、变化的幅度尚未达到对人类生活和生湖治及湖 周右限区域生态环境的悪化中，人类不正确的活动方式占了很大比重。
\end{abstract}

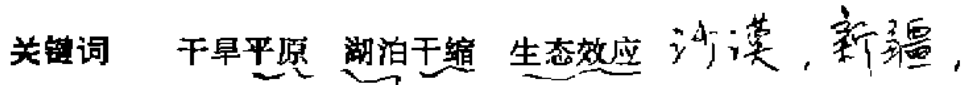

50 年代初至 80 年代初, 新疆的湖泊发生了较大的变化，最明显的是平原区湖泊的干涸

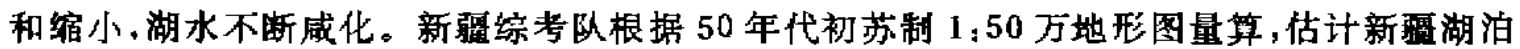
总面积为 $9700 \mathrm{~km}^{2[1]}$ 。中科院南京地理与湖泊研究所根据 70 年代的地形图及航片资料量 算,估计新疆湖泊总面积到 70 年代未已喊少到 $5072 \mathrm{~km}^{2}$ 左右, 比 50 年代㺂少了 $48 \%$; 但仍 占全国湖泊总面积的 $7.1 \%$, 居全国第四位 ${ }^{[2]}$ 。

从 50 年代到 80 年代初，新疆湖泊变化的总趋势是: 平原沙漠区的湖泊趋于退缩和干 涸，山区湖泊略有退缩，个别湖泊(如艾西曼湖)因灌激回旧水的不断排入而扩大 ${ }^{[3]}$ 。

湖泊退缩原因，有两类。一类是自然原因，亚洲中部在上世纪小冰期结束后，气侯不仅一 直在变暖, 面且有进一步变干的趋势 ${ }^{[1]}$ 。由于气侯波动是一个较为缓慢的过程, 它对湖泊退 缩的影响也是缓慢的.因此,它不可能成为平原沙漠区湖泊在短期内迅速退缩的主要原因。 第二类原因是人类活动，主要是人类在湖泊上、中游地区引水灌莇，造成湖泊退缩甚至干涸。 这在干旱区的平原沙漠区中较为常完，大量的调亘资料也证实了这一点。

湖泊干缩不可避免地对湖泊生态系统本鸟及湖周地区的生态环境造成了一定的影响。 在论及这种影响时, 首先应当把湖泊所在流域的生态环境的恶化与湖泊本身及湖周区域生 态环境的变化区仔开来; 其饮,在论及环境变化的原因时，应当把导致湖泊所在流域生态环 境恶化的原因与导致湖泊自身生态环境变化的原因区你开来; 第三,在论及湖泊环境变化的 原因时,应把湖泊退缩或干涸所引起的生态环境的变化与由于人类其它不正确的活动方式 所引迅的湖泊生态环境的变化区分开来。下面我们将从五个方面来探讨这种影响。

\section{一、对湖区土地的沙漠化影响}

目前已干涸或已退缩的湖泊或湖周地区，或多或少、或轻或重地都存在着沙漠化现象，

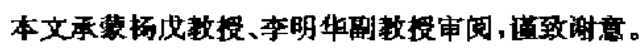

本文于 1992 年1月11日收回, 1992 年5 月 30 日改回。 
而且不少区域从 50 年代到 80 年代有不断加剧的趋势。现就人们比较关注的三个湖泊及其 湖周的沙漠化现象作一分析。

\section{1. 罗布泊及共周围地区的沙漠化}

首先应当加以区别的是罗布泊地区和罗布泊现代湖盆是两个不同的概念。首者一般指 东到玉门关、西至库尔勒, 北达库鲁塔格山脉, 南抵若㒸、米兰一带的广大区域; 而罗布泊湖 水面积 1931 年实测为 $1900 \mathrm{~km}^{2}\left(1942\right.$ 年苏制 $1: 50$ 万地形图上为 $3006 \mathrm{~km}^{2}$,)。在 1972 年美 国卫星拍摄的盟片中,罗布泊被首次证实已经干涸。

罗布泊地区近期沙漠化剧烈发展的地区在塔里木河下游库尔勒至罗布庄平原一带。引 起沙化的主要原因是水源断绝、人类波坏植被及盲目开星所致,沙源主要是裁地起沙。其次, 罗布泊地区有大片雅丹地貌，距现代湖盆较近且面积最大的一片在楼兰古城周围，面积约 $1800 \mathrm{~km}^{2}$ 。第三, 干涸后的罗布泊湖盆本身是否遗到了侵蚛? 据罗布泊综合考察队 1980 1981 年实地考寮结果, 以罗布泊现代湖盆为中心的大片区域, 分布有约 $20000 \mathrm{~km}^{2}$ 的盐壳, 在各种盐壳中, 以质地坚硬的厚层 $(30-70 \mathrm{~cm}$ ) 龟裂盐壳(用十字镐都很难挖动)分布最为广 泛,占据现代湖盆的大部分,在自然状态下,被风蛨的可能性很小,而新近湖水退出的湖盆盐 壳较松软, 厚度 $10-20 \mathrm{~cm}$, 较易遭到风蚛 ${ }^{[5]}$ 。上述事实说明, 现代罗布泊干涸后的湖盆本身 提供的沙源很少、所以未导致大面积䏚化现象的发生，但值得注意的是,楼兰古城周围的大 片雅丹地貌系成于古湖相沉积区域,因此,在百年至干年的时间尺度上,千洞的湖床被侵蚛 而引起的沙化仍然不能忽规。

\section{2. 艾比湖地区的沙漠化}

艾比湖在 50 年代初尚有 $1070 \mathrm{~km}^{2}, 80$ 年代退缩为 $520 \mathrm{~km}^{2}$,目前大致趋于稳定。

这一地区的沙漠远在现代艾比湖干缩之前就已形成, 主要集中在古尔图河和奎屯河之 间以及艾比湖洼地的东南部，前者对乌伊公路 $387 \mathrm{~km}$ 处构成威胁; 后者对北埴铁路西段构 成威胁。该区现代少漠化现象的加剧，主要是人类破坏地表植被所致。50 年代初，该区域分

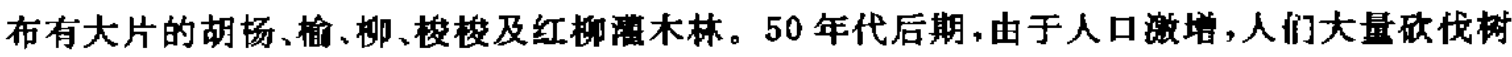
木用于取眼、烧饭。从 60 年代初到 70 年代末, 当地居民在艾比湖的西、南、东部毁林草后开 荒约 $2 \times 10^{4} \mathrm{hm}^{2}$, 后来采取种种措施, 但仍有弃耕地 $6700 \mathrm{~km}^{2}$ 左右。而在湖的南部 82 团驻地 附近, 由于当地居民的不恰当活动，沙漠化面积已达 $56.8 \mathrm{~km}^{2}$ 。干涸的湖床为沙漠化过程提 供了多少沙源? 目前尚难估算清楚。据扬川僡引自潘汉喍资料，在近 $700 \mathrm{~km}^{2}$ 的干湖底, 近 10 年来被大风吹走的表层泥沙达 1000 多万 $\mathrm{m}^{3[6]}$, 平均每年约 100 万 $\mathrm{m}^{3}$ 。据此推算，该地区年 平均吹蚀速率为 $1.43 \mathrm{~mm} / \mathrm{a}$, 低于罗布泊地区 $3.5 \mathrm{~mm} / \mathrm{a}$ 的年平均吹蚛速率 ${ }^{[\mathrm{b}]}$. 精河县和乌 苏县 70 年代比 60 年代的大风日数平均每年分别减少 20.5 天和 5.0 天,沙尘堭日数反而堷 多 3.9 天和 2.1 天,这在某种程度上说明了该地区沙化趋势。据中国科学院新囬生物土壤䏚 漠研究所对乌苏少漠的实测资料，䢂径小于 $0.05 \mathrm{~mm}$ 的沙粒反占 $1.5 \%$ ，而只有小于 $0.05 \mathrm{~mm}$ 的沙䢂才可以意浮状态被较大距离搬运 ${ }^{[]]}$。因此, 这片沙漠形成及沙化趋势的加剧 与现代艾比湖的干缩关系甚小。

由于艾比湖位于阿拉山口下风向,是全萢大风日数 $(164 \mathrm{~d} / \mathrm{a})$ 最多的区域之一,湖底以细

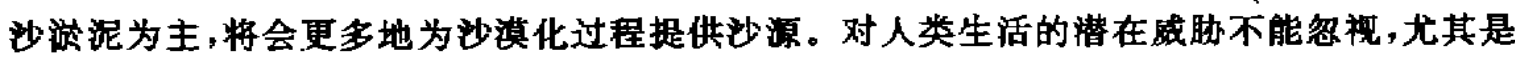
对北临铁路的威胁。有关保护公路和铁路的规则正在实施中。 


\section{3. 橧海湖(指布伦托海和吉力湖)周国的沙漠化}

沙漠主要分布在乌伦古河古三角洲上。40 年代该区域沙漠面积为 $140 \mathrm{~km}^{2}, 60$ 年代初， 由于大规模的农垩活动,减少到 $106 \mathrm{~km}^{2}$; 到 70 年代中期, 因水源不足而弃耕、沙化面积又扩 大到 $139.4 \mathrm{~km}^{2} ; 1985-1886$ 年考察时,沙化现象又有所加剧 ${ }^{[8]}$ 。楅海湖从 50 年代到 80 年代 初、大约退缩了 $60-70 \mathrm{k} \mathrm{m}^{2}$ 。除与河三角洲西部近湖地带沙化过程的加剧与湖泊退缩有关 外、其余区域尚未发现与湖泊退缩有明显关系的沙化现象。

除上.述湖泊外，还有一些小湖(如塔里木河下游的乌棕库勒湖群)干涸较早, 沙化程度相 对比较严重。古尔班通古特沙漠南缘湖群除艾比湖外，全部干涸，湖周也存在着沙淇化现象。 但上述沙化现象对人类生产生活影响较小。

上述分析表明、已经干涸的湖泊和处于退缩状态的湖泊、其干涸的湖床尚未发生大面积 沙化现象。到目前为止，裸露的湖床所提供的沙源是有限的 (艾比湖干涸的湖床相对而言提 供的沙源较多)；湖周地区沙淇化现象的加剧主要是人们破坏地表植和不适当的开晎造成 的; 但干淍的湖床会成为潜在的沙涼(艾比湖干涸的湖床已成为新的沙湶之一)，现有的湖面 积如继续退缩、沙化现象可能会有所加剧。

\section{二、对野生植物的影响}

目前关于这方面研究资料较多的是罗布泊地区。整个罗布泊地区在塔里木河断流之后， 高等植物由 55 种减少到 36 种。其中有 5 种水生和湿生植物的消失与罗布泊干涸有直接的 因果关系。另外，盐干屈莱这种植物据目前所知原来在我国只分布在罗布泊地区,这种植物 现在已从我国的植物区系资源中消失了。此外，该地区的植被类型向盐生和沙生方向发 展 ${ }^{[0]}$.

关于该区是否有高等植物物种灭绝的问题，除了盐千屈菜这种植物尚不能完全肯定在 世界其他地区是否还有分布外，其余 54 种植物都不是罗布泊地区的特有种。因此,目前还不 能肯定地说该地区有物种(高等植物)灭绝现象、更不存在由于湖泊干涸而引起物种灭绝现 象。

黄培佑等对干洞后的玛约斯湖周围的植被进行了考察,其结论是: 湖泊干涸末导致大范 围生态环境的根本性改变,主要表现在以梭梭为主体的自然椬被保持着自然更新能力。但湖 泊干涸对近湖区的低地沼生植物群落影响较为朋显,而近期湖泊干涸直接影响的植物群, 仅 限于耐盐性较强的灌生植物如芦苇等 ${ }^{[10]}$ 。

湖泊退缩也引起了植物的某些变化,受影响最显著的莫过于湖周芦苇群落. 博斯湖、

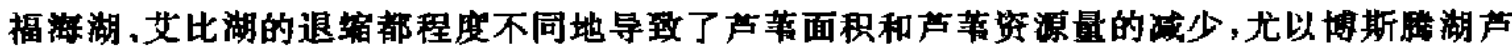

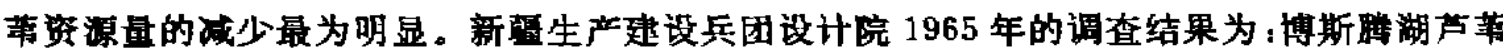
面积为 $300 \mathrm{~km}^{2}$, 产量为 $40 \times 10^{4} \mathrm{t}$; 1981 年自治区农委组织考察队对开都河流城进行了考寮，

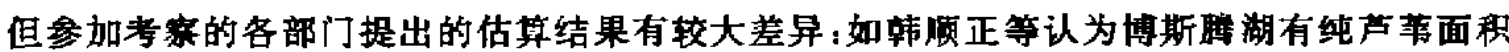
$354.7 \mathrm{~km}^{2}$, 总资源量为 $31.6 \times 10^{4} \mathrm{t}^{[11]}$ ，丁志等根据 1976 年 10 月的卫片估算、芦苇面积为 $310 \mathrm{~km}^{2}$, 产量为 $34.3 \times 10^{4} \mathrm{t}, 1981$ 年实地考察后计莽，产量为 $26.6 \times 10^{4} \mathrm{t}^{[12]}$ 、袁方策等根据 卫片及 1981 年实地考察计算，得出芦节面积为 $413 \mathrm{~km}^{2}$, 总产量为 $24.73 \times 10^{4} \mathrm{t}[19]$ 面自治区 开都河流域考察队芦苇组 1981 年的考察面积为 $200 \mathrm{~km}^{2}$, 产量为 $25.1 \times 10^{4} \mathrm{t}$ 。可见，在当时 
的条件下，要准确地估算出芦苇资源量尚有不少困难。但对标准茅的年产显的认识相对一 致，即在 $22 \times 10^{4} \mathrm{t}$ 至 $25 \times 10^{4} \mathrm{t}$ 之问。导致芦苇产量下降的原因，主要是小湖区因河流上游水 利工程的建而失去了河湖经常泛湤这一必要条件。芦苇生长虽与积水深度及流速有密切 关系，但泥炭的不断增厚也是芦苇退化的重要因来。博斯湖水位 1958 年之前稳定在 $1048 \mathrm{~m}$ 之上, 1981 年下降到 $1047.5 \mathrm{~m}, 1986$ 年降到近 40 年来最低点 $1044.82 \mathrm{~m}$, 这导致了芦

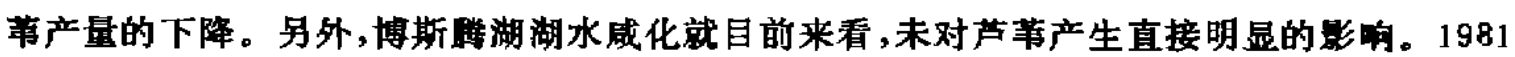
年考寮以调查时发现，全湖矿化度最高在黄水沟,而该区是湖区芦苇生长最好的区找，一类 芦苇面积占全湖一类芦革面积的一半，而产量则占 $63.56 \%$ 。

福海湖在“引新济海”渠扩建工程完工后, 水位大幅度回升, 水生植被总面积由 1985 年 的 $813 \mathrm{~km}^{2}$ 增加到 1989 年的 $4365 \mathrm{~km}^{2}$, 总偖量由 $7700 \mathrm{t}$ 增加到 $41750 \mathrm{t}$ 。其中芦苇占面积的 $81 \%$ 和总偖量的 $68 \%$ 。这从反面证明了湖泊退缩对水生植被的显著影明[14]。

由上述分析可知，受湖泊干涸和退缩影响较大的主要是以芦革为主的水生植物。

\section{三、对野生动物的影响}

这方面的资料目前很少, 只作一简要分析。据研究, 艾比湖一带有鸟类 39 科 133 种, 兽 类 12 科 36 种,两栖类 2 科 2 种，爬行类 5 科 5 种。与湖泊生态环境关系较大的主要是鸟类。 多种水全栖息于此，中亚和西伯利亚等地的埃内有不少以此为中转站,过去每年在此过往 的鸟类达百万之众。近年来由于人类捕猎和湖面退缩，鸟类数量迅速下降 ${ }^{[16]}$ 。类似的情况在 博斯滕湖和福海湖周围也有发生,只是范围和程度大小不同而已。据此推测: 罗布泊和玛约 斯湖干涸前也有不少鸟类在当地栖息。在罗布泊湖盆区，考寮队发现了多种水全和一种证 的残䯓，现仅见少数偶然分布的 7.8 种鸟类的个体和在当地捕食的楼舆群。

一般来说，动物物种的多样性和种群数量与其栖息地和活动范围面积的大小成正比关 系。湖面退缩甚至干浻有可能使动物栖息地缩小,这将给动物带来不利影响，尤其是对鸟类 影响较大。但绝大多数动物对栖息地具有较强的选择能力,当一地环境恶化时,它们会自动 向其它地区午移。例如，现在罗布泊地区西北的孔雀河一塔里木河下游,水源与植柀相对丰 富,成为水禽的集中分布区和马鹿分布中心,并栖息有多种鸟类。在芝比湖区芦苇沼泽地带 和博尔塔拉河及精河人湖河口一带的湖面上,因类特别集中，也在一定程度上说明了问题。

从现有的为数不多的资料初步推论：湖泊干缩对鸟类影响较大，对其它陆生动物影响

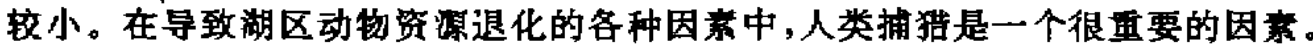

\section{四、对鱼类的影响}

目前探讨较多的是福海湖 (指布伦托海和吉力湖) 鱼类资源的变化。该湖 1970 年鱼类总 产量达 $4500 \mathrm{t}$ ，约占当年全愠鱼类总产量的 $50 \%, 1976$ 年仅为 $800 \mathrm{t}$ ，近年来在 $2000 \mathrm{t}$ 左右推 䧃。此外，鱼获物结构亦发生了明显变化。据皇振纲研究，贝加尔雅罗鱼和河蛅在鱼获物中 所占的量量百分比: 1961 年分别为 $70 \%$ 和 $20 \%, 1974$ 年为 $50 \%$ 和 $35 \%, 1984$ 年则变为 $30 \%$ 和 $40 \%$ 。鱼获物中鱼类个体档小，低龄鱼占了绝大部分 ${ }^{[16]}$ 。关于引起上述变化的原因， 
人们已经列举出很多, 但对各种原因所占的比重末加区分。笔者 1985 年实地进行调查后认 为:

1. 导致福海湖鱼产量较大波动的主要原因是过度捕捞 理由有三:(1)从鱼类生态学分 析, 在湖泊环境虽有变化但变化不大的情况下 (唯一变化较大的因素是大、小海子之间拦河 闸的建)，能使鱼产量陡升陡降的因素唯有过度捕措。这种现象在全国不少大、中型湖泊中 部出现过。(2)鱼类个体道小、低龄鱼占了很大比例这一事实说明: 由于过度捕措, 鱼类种群由 耕余群体向补充群体转化。(3)㴔业管理失控,网目不断缩小,水下大拉网亚重地破坏了湖中 沉水植物的䇣衍, 导致了草上产卵鱼类的需殖及其幼鱼的索訴场所减少, 在产卵期和产卵区 大量捕杀亲鱼的现象十分蓄遍，时至今日，这种现象仍末绝迹。

2.小海子和大海子之间拦河问的结建 (1974 年建成) 对鱼类的危害有二：(1)阻断了 贝加尔雅罗鱼等回游性鱼类的生殖回游通道。虽然目前贝加尔雅罗鱼在湖区周围仍可产卵， 但有迹象表明, 其产卵量和成活率均有一定的下降。(2)中海子的干涸与此有很大关系, 这使 鱼类丧失了一片优良的产卵场。

3. 水位下降、湖面退缩，近生水城水草怙死，鱼类的栖息、整饵、产卯场因之成少一些 研究表明：鲤鱼和狗鱼对水位变动非常敏感，在水位稍许下降的情况下,迅速停止产卯。但这 几种鱼在鱼获物中所占比例原来就较小。

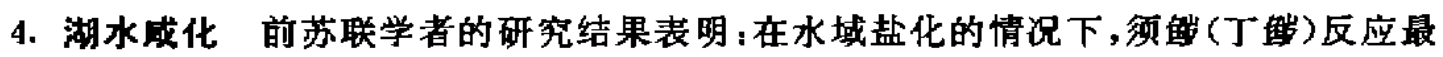

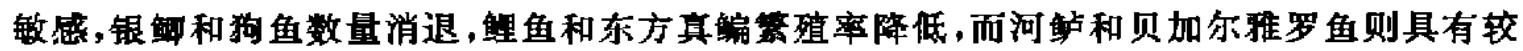
强的抗盐能力。但每一种鱼类能够适应的盐愊有多宽, 尚末见有详细资料报导。前苏联水生

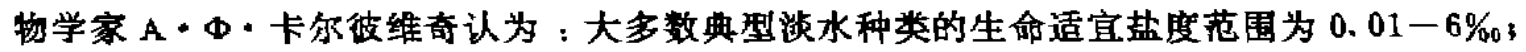
$5-8 \%$ 的盐度是淡水动物区系和海水动物区系的蓝度界线; 淡水鱼类最佳䇣殖效果出现于 $2-3 \%$ 的盐度水体。这表明, 福海湖盐度 $(<4 \% 0)$ 仍在鱼类适应范围之内 ${ }^{[17]}$ 。

福海湖 1966 年仅有土著鱼类 7 种; 1965-1967 年,福海渔场从布尔津引进了鲤鱼,并 带入了一些其它种类的鱼苗; 1970 年冬, “引新济海”柴开通, 顺尔剂斯河鱼类相继进入, 鱼 类由 7 种渞加到 15 种(南京地理与湖泊研究所 1987 年调查时又采到杂交种 1 种)。而土著 鱼类须和银的城少可能与外来种的移入有很大关系。此外，由于 1970 年“引激海”桇 开通后,每年有 $4.5 \times 10^{8} \mathrm{~m}^{3}$ 的淡水注入布伦托海,因此, 鱼产減产与湖水感化关系甚小,这 从多年来湖中贝加尔雅罗鱼和河的卢的优势种群地位末变,也可说明。

把福海湖鱼产量的变化视为鱼类资源衰退的观点是值得商榷的。所谓资源衰退，是指年 捕措量持续大于鱼类年最大补充量。福海湖在 1958 年前基本上未得到开发,因此在其后的 10 多年里，产量持续增长是正常的现象，因为湖中鱼类多年积累，耕余群体很大。衡量鱼类 资源量的恰当标准是其年最大持续补充量(或称年更新量), 福海湖从 1973 年至 1987 年 (“引新流海”集扩建工程于 1987 年 11 月完成)产量一直在 2000 左右非淘, 说明其鲁类资 源量目前大致处于稳定状态。

据此推论: 湖泊干缩和湖水感化至少在目前看来, 未对鱼类产生较大影响。

博斯湖鱼类的变化原因主要是过度捕描和新种移入。前者在未移殖鱼类之前曾引起 鱼产量陡升陡降，后者则造成土著鱼类迅速減少。移殖鱼类(河呫)迅速增长，到 80 年代初， 河战已占到全湖鱼产量的 $70 \%$ 以上，鱼产量也由移真前最高产量 $1500 \mathrm{r}$ 增至目前的 $2000 \mathrm{t}$ 以上. 可见,这与湖泊退缩关系不大。 


\section{五、对局地气候的影响}

目前关于这方面的研究较少。已干涸的湖泊由于远离人类居住区、尚末发现当地气侯有 大的改变, 也末发现这种改变对人类生活产生的影响。博斯湖和福海湖由于退缩面积有 限，因而也不大可能对气候产生什么大的影响。艾比湖退缩面积较大,对局地气候可能有一 定影响。虽然有资料表朋艾比湖地区降水自 50 年代以来有减少的趋势，但这与北㗼地区 50 年代以来的气候干䁔化趋势是一致的。湖泊退缩无䟥会对局地气候产生一定的影响，但根据 各种资料分析，在新临极端干旱的大气恅背景下,这种影响是十分有限的。

\section{六、结语}

由上述可知，湖泊干缩对生态环境的影响主要表现在:干涸后的湖床为沙漠化过程提供 了一定的沙源; 湖泊干缩对水生植物影响比较朋显,对其它植物影响较小，对鸟类影响比较 大, 对其它动物影响不大、对鱼类有一定影响; 湖水咸化在目前尚末看到对环境有什么直接 朋显的影响。虽然目前湖泊干缩对环境尚末产生较大影响，但现有湖泊如果继续退缩,其对 环境的影响将会逐渐增大。 80 年代中期以来，平原区湖泊退缩状态已被初步遏制，博斯滕 湖和福海湖水位均有一定的㷋复。

湖泊干缩对生态环境的影响是一个比较复杂的问题,造成湖区生态环境恶化的原因是 多种多样的,只有正确区分和充分认识这些原因,才能全面地认识湖泊干缩所引起的生态效 应。

\section{省文献}

[1] 部敏斿主编。新造水文地理。北京,科学出版社,1966。

[ 2] 王洪道等。中国湖泊资湶。北京、科学出版社,1989。

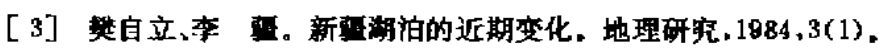

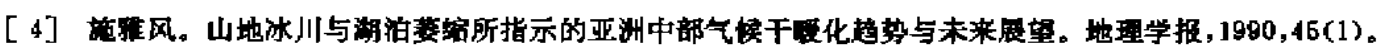

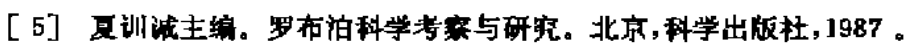

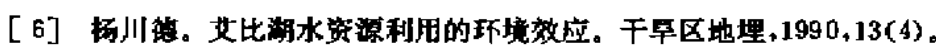

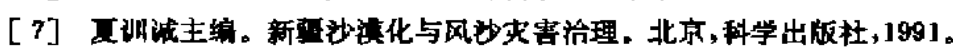

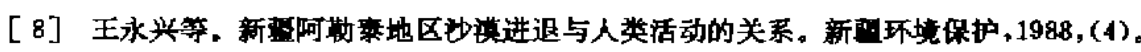

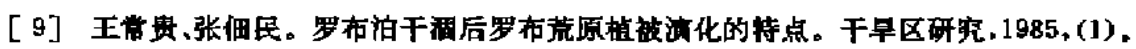

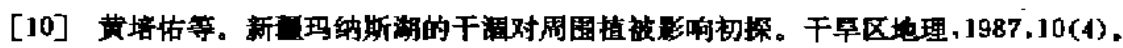

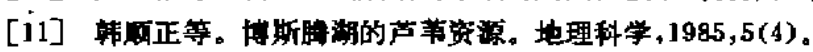

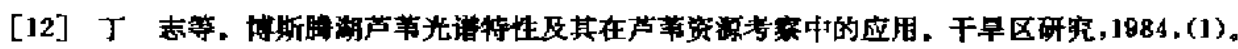

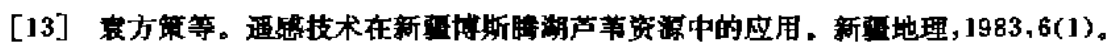

[14] 车文胡、扬漳心。与伦古湖水生植被研究。海洋与湖泪、1993,24(1)。

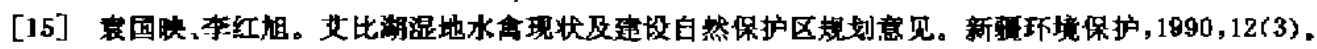

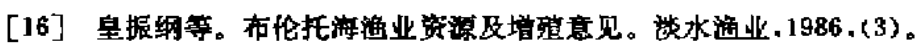

[17] A， D. 卡尔伎维奇著(杜佳垠译)，水生生物移植则化理论与实践。北京，科学出版社，1986。 


\title{
ENVIRONMENTAL EFFECTS RESULTED FROM THE SHRINK- ING AND DRIED-UP OF LAKES IN PLAIN AND DESERT AREA IN XINJIANG AUTONOMOUS REGION IN CHINA
}

\author{
Wang Xiaofeng Zhang Haisheng

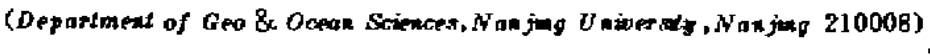

\begin{abstract}
Lakes in the plain and desert area in Xinjiang autonomous region have been shrinking greatly due to irrigation since the 1950 s, and some lakes have even dried up, resulting in such environmental effects as land desertization, fauna-flora degradation, fish-yield reduction and the local climate changes. Since these effects were overestimated and the main causes to arise effects mentioned above were confused, further discussion is made on these effects comprehensively.
\end{abstract}

Key words Arid area,shrinking and dried-up lakes in plain and desert area, environmental effects

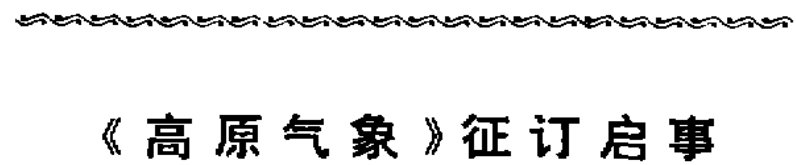

璃原气象是中国科学院兰州高原大气物理研究所主办的大气科学领域里高级性的学术刊物。主要 反映和交流高原气象领域的最新科研成果, 以推动和促进高原气象学科研究的进一步发展。

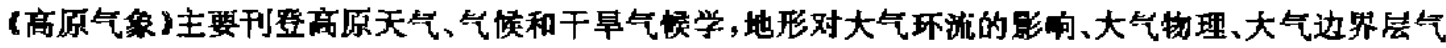

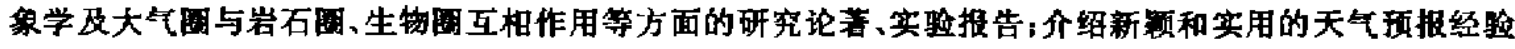
和方汰以及选登一些国内外的学术动态等。

读者对凂为从事本学科的科研工作者、大专院挍师生和气象台站的预报员等。同时也可供地理、冰川、 地质、地展和农业科学等研究领城的研究工作若参阅。

（高原气象〉为季刊，每期定价 5.5 元，全年定价 22 元. 全国各地邮局 10 月前后开始办理订阅手续,邮 发代央:54-43。国外由中国国际国书贸易总公司负责发行，代号、Q808。 